\title{
Differentiation between Normal and Abnormal Cases by Maximum Frequencies of Images of Breast Tissues
}

\author{
Salim J. Attia ${ }^{1}$, Ziad M. Abood $^{2}$ and Ibrahim R. Agool ${ }^{3}$ \\ ${ }^{1}$ Department of Basic Sciences, College of Dentistry, University of Baghdad, Iraq \\ ${ }^{2}$ Department of Physics, College of Education, Al- Mustansiryah University of Baghdad, Iraq \\ ${ }^{3}$ Department of Physics, College of Science, Al- Mustansiryah University of Baghdad, Iraq \\ j.salim08@yahoo.com
}

\begin{abstract}
This study focuses on detection of the abnormality of various digital images taken from breast tissues and applying of maximum frequency calculation. It is found that this method gave good result to get the goal of research. The images were calculated for comparing between normal images and abnormal images by maximum values that each cells image reach to. Collection of 100 images is chosen to apply this method. Many research deal with this state [1][2][3][4].
\end{abstract}

Keywords: Histogram, Maximum Frequency, Breast tissue and Digital Image.

\section{Introduction}

The diagnosis of diseases takes progressing care by analyzing techniques in both developing technologies and advanced software to aid and supports the cytologists' efforts to early detect of fatal illnesses like cancer as effective way to discard it. There is a surge of developments, such as computer programs that can indicate suspicious areas. [5]

The enormity of the global healthcare costs as a result of cancer infliction cannot be overemphasized. There are more than 100 types of cancers; any part of the body can be affected. More than 11 million people are diagnosed with cancer every year, and it is estimated that there will be 16 million new cases per year by the year 2020. [6]

Breast cancer is the second largest cancer killer of North American women. Its causes are still largely not understood; however, both genetic and environmental factors have been implicated. Currently, the most effective approach to reducing mortality from breast cancer is through early detection. [5]

\section{Methodology}

A total of 100 colored images including normal and abnormal cases have been used, these are listed in table 1. Samples of obtained images are explained in Figure 1.a which represents malignant image and 2. $b$ of benign image. 
Table 1: Data table used in study

\begin{tabular}{|l|l|l|c|}
\hline & \multicolumn{2}{|l|}{ Cells' images } & $\begin{array}{c}\text { Total number of } \\
\text { images }\end{array}$ \\
\cline { 2 - 3 } & Normal & abnormal & 100 \\
\hline No. of images & \multicolumn{2}{|c|}{50} & \\
\hline Image Size & \multicolumn{2}{|c|}{ Different sizes } \\
\hline Magnification & \multicolumn{2}{|c|}{$400 \mathrm{X}$} \\
\hline
\end{tabular}

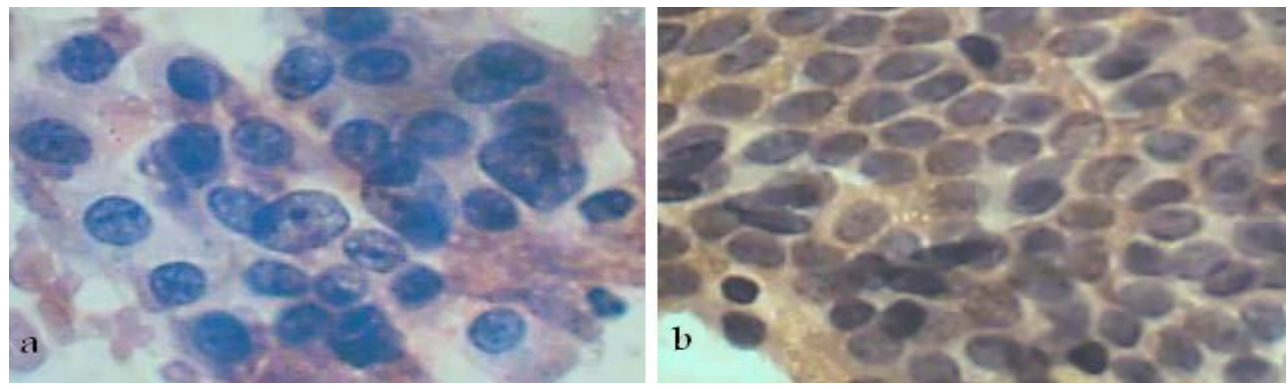

Figure 1: a- abnormal image, b- normal image

Histogram measures: The histogram of an image is defined as a vector that contains the count of the number of pixels in the image at each gray level [7]. The histogram provides a description of the distribution of intensity values within the object. When normalized by the size of the image, the histogram yields the (discrete) Probability Density Function (PDF) of the gray levels. Thus, measures derived from the normalized histogram of an image of an object provide statistical descriptors characterizing the gray-level distribution of the object [6]. We consider the discrete (PDF) [8], inother words the maximum frequencies include the number of pixels in the image at each gray level divided by total number of pixels in image as explained in equation 1 :

$$
P D F(n)=\frac{h(n)}{N}
$$

Where $h(n)$ is the number of pixels with $n$ value and $N$ is the total number of pixels.

So the certain gray level which has highest number of pixel in image represents maximum frequency value expressed in percent ratio. This calculation is taken for three main bands of image Red, Blue and Green.

\section{Results and Discussion}

The maximum frequencies getting from the histogram of images as seen in Figure1 explain that average values of maximum frequency of the normal cells in three band colors $R, G$ and $B$ are bigger than those of abnormal ones. The $\mathrm{R}$ band has smallest value of maximum frequency and the $\mathrm{G}$ band has the biggest.

Besides that, the tops of RGB bands are near from each other but relatively far in abnormal as see in Figure 2. That reflects the similarity in images of cells because the repetition of same pixel's value in image, so the normal images of cells have much similarity because they have bigger maximum frequency and the abnormal images of cells have relatively little similarity because they have smaller maximum frequency and in compatible with what we guess the situation in abnormality case which is characterized by less similarity and this reflects the disorder state in it. 

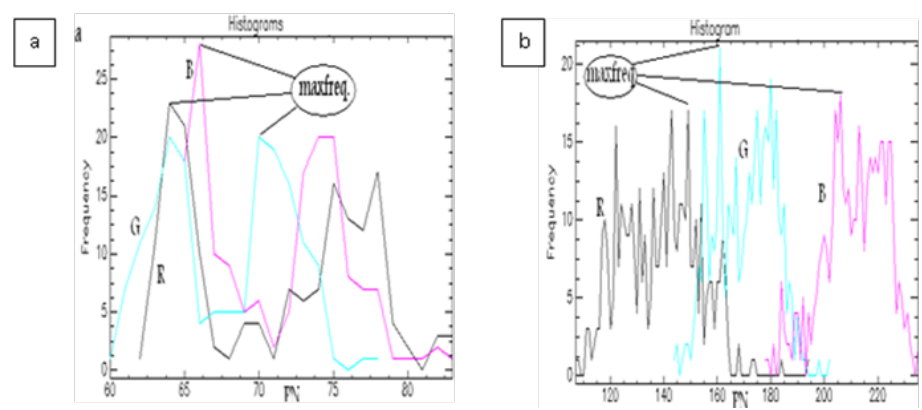

Figure 2: Histogram of a) normal b) abnormal image

The scatter plots of the maximum frequency feature show the intersection between normal and abnormal cells for RGB bands as see below in table 2 and Figure 3.

The overlapping ratio between benign and malignant of maximum frequency is $5 \%$ for $\mathrm{R}$ band, $13 \%$ for $\mathrm{G}$ band and $31 \%$ for $\mathrm{B}$ band.

Table 2: min and max values of max. freq. for normal and abnormal cells

\begin{tabular}{|c|c|c|c|c|c|c|}
\hline & $R$ & & $\mathrm{G}$ & & $B$ & \\
\hline & $\begin{array}{l}\text { Benign } \\
\text { (min-max) }\end{array}$ & $\begin{array}{l}\text { malignant } \\
\text { (min-max) }\end{array}$ & $\begin{array}{l}\text { benign } \\
\text { (min-max) }\end{array}$ & $\begin{array}{l}\text { malignant } \\
\text { (min-max) }\end{array}$ & $\begin{array}{l}\text { benign } \\
\text { (min-max) }\end{array}$ & $\begin{array}{l}\text { malignant } \\
\text { (min-max) }\end{array}$ \\
\hline $\begin{array}{l}\text { Maxfreq. } \\
\left(x 10^{-2}\right)\end{array}$ & $\begin{array}{ll}6.2963 & - \\
23.7374 & \end{array}$ & $\begin{array}{l}2.0475 \\
7.4000\end{array}$ & $\begin{array}{l}6.8323 \\
33.913\end{array}$ & $\begin{array}{l}2.4570 \quad- \\
10.8333\end{array}$ & $\begin{array}{ll}5.4945 & - \\
20.4167 & -\end{array}$ & $\begin{array}{l}2.6208 \\
11.0122\end{array}$ \\
\hline
\end{tabular}
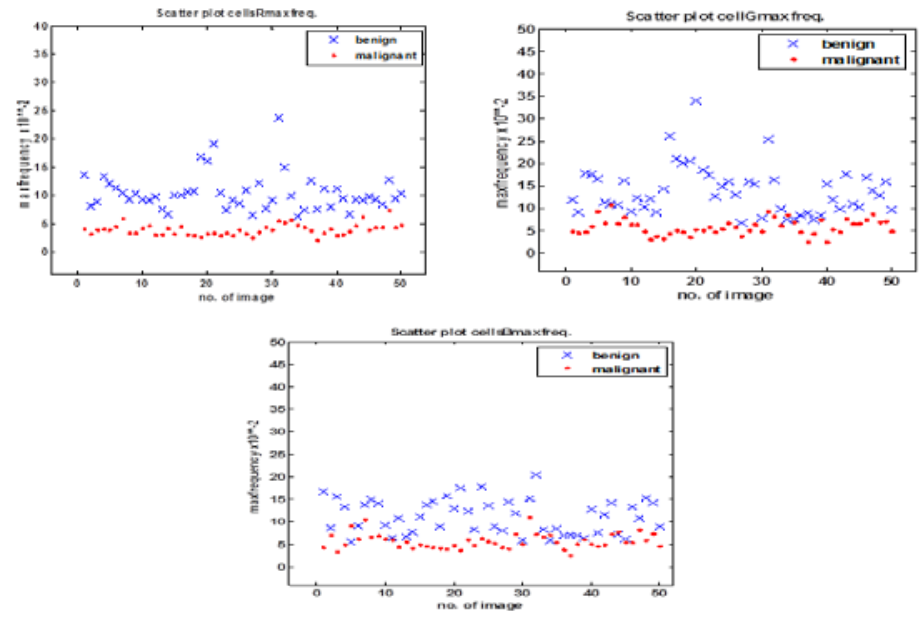

Figure 3: Scatter plot of max. Frequency of R, G and B bands of cells images

\section{Conclusion}

In this study the images of human breast tissue are taken and the cells images in them are captured to determining the maximum frequency of them. The values of maximum frequency for $R, G$ and $B$ bands gave good differentiation between normal and abnormal images and the average overlap ratio of three band of color of images is about $16 \%$. 


\section{ACKNOWLEDGEMENT}

The authors would like to thank the Directorate of Al-Imam Ali Hospital in Baghdad/ Iraq for the good facilities during this study.

\section{REFERENCES}

[1] Nuryanti Mohd. Salleh, Harsa Amylia Mat Sakim and Nor Hayati Othman, "Neural Networks to Evaluate Morphological Features for Breast Cells Classification", International Journal of Computer Science and Network Security, Vol.8, No.9, pp. 51-58, September 2008.

[2] Lukasz Jelen, Thomas Fevens and Adam Krzyzak, "Classification of breast cancer malignancy using cytological images of fine needle aspiration biopsies", Int. J. Appl. Math. Comput. Sci., Vol. 18, No. 1, pp. 75-83, 2008.

[3] Dundar, M.M., "Computerized Classification of Intraductal Breast Lesions Using Histopathological Images", Biomedical Engineering, IEEE Transactions, Vol. 58, Issue 7, pp. 1977 - 1984, 2011.

[4] Tatari F, et. al, 2012, "Fuzzy-probabilistic multi agent system for breast cancer risk assessment and insurance premium assignment", J. Biomed. Inform., 2012.

[5] Margie Patlak, Sharyl J. Nass, I. Craig Henderson, and Joyce C. Lashof, "Mammography and Beyond: Developing Technologies for the Early Detection of Breast cancer", National Academy Press Washington D.C., 2001.

[6] John C. Russ, "The Image Processing Handbook", Third Edition, CRC Press LLC, 1998.

[7] Jonathan M. Blackledge and Dmitry A. Dubovitskiy, "A Surface Inspection Machine Vision System that Includes Fractal Texture Analysis", ISAST Transactions On Electronics And Signal Processing, 2008.

[8] Qiang Wu, Fatima A. Merchant and Kenneth R. Castleman, "Microscope Image Processing", Elsevier Inc. 2008. 